\title{
Principles of Motor Learning in Ecological Dynamics A comment on Functions of Learning and the Acquisition of Motor Skills (With Reference to Sport)
}

\author{
Keith Davids*,1,2, Ian Renshaw ${ }^{1}$, Ross Pinder ${ }^{3}$, Duarte Araújo ${ }^{4}$ and Luis Vilar ${ }^{4}$ \\ ${ }^{1}$ School of Exercise and Nutrition Science at Queensland University of Technology, Australia \\ ${ }^{2}$ Faculty of Sport and Health Sciences, University of Jyväskylä, Finlan \\ ${ }^{3}$ University of the Sunshine Coast, Australia \\ ${ }^{4}$ Faculty of Human Movement Science at the Lisbon Technical University, Portugal
}

\begin{abstract}
This paper provides a commentary on the contribution by Dr Chow who questioned whether the functions of learning are general across all categories of tasks or whether there are some task-particular aspects to the functions of learning in relation to task type. Specifically, they queried whether principles and practice for the acquisition of sport skills are different than what they are for musical, industrial, military and human factors skills. In this commentary we argue that ecological dynamics contains general principles of motor learning that can be instantiated in specific performance contexts to underpin learning design. In this proposal, we highlight the importance of conducting skill acquisition research in sport, rather than relying on empirical outcomes of research from a variety of different performance contexts. Here we discuss how task constraints of different performance contexts (sport, industry, military, music) provide different specific information sources that individuals use to couple their actions when performing and acquiring skills. We conclude by suggesting that his relationship between performance task constraints and learning processes might help explain the traditional emphasis on performance curves and performance outcomes to infer motor learning.
\end{abstract}

Keywords: Learning design, functions of learning, ecological dynamics, performance contexts.

\section{INTRODUCTION}

An important concern for sport scientists interested in skill acquisition and learning processes regards the design of practice task constraints for performers of various levels of skill. To aid their understanding of these processes, and support their practices, sport scientists often turn to the extant motor learning literature [1]. On reading the stimulating paper of Dr Chow in this special issue, "Functions of Learning and the Acquisition of Motor Skills (With Reference to Sport)", an interesting question emerges over how best to interpret data from empirical studies of motor learning. In their paper, Dr Chow correctly point out that previous research on motor learning functions is characterised by studies in contexts other than sport, including laboratory settings and industrial complexes. Indeed, Dr Chow highlighted that: "There is the long-standing question as to whether the functions of learning are general across all categories of tasks or whether there are some task-particular aspects to the functions of learning in relation to task type. For example, as we consider the learning of sports skills, do we anticipate $a$ priori that the principles and practice of the acquisition of sport skills are different than what they are for musical, industrial, military and human factors skills?"

*Address correspondence to this author at the School of Exercise and Nutrition Sciences, Queensland University of Technology, Australia;

Tel: +610731388744; Fax: +610731383980;

E-mail:k.davids@qut.edu.au
These are interesting comments of relevance to sport scientists, sport educators and pedagogues. The broad theoretical concern is on the generality of the functions of motor skill learning across motor tasks. They may shape how practitioners interpret the findings of motor learning research in the quest to enrich their pedagogical practice. Does it matter that, as the authors put it: "...our ideas about the functions of learning sports skills are based as much or more on the learning curves of motor task categories other than those of sport"? Put in a technical way: are timescales for motor learning generalisable between different performance task constraints like industrial manufacturing, human-computer interactions or sport?

In this commentary we argue that ecological dynamics contains general principles of motor learning that can be instantiated in specific performance contexts to underpin learning design. In this proposal, we highlight the importance of conducting skill acquisition research in sport, rather than relying on empirical outcomes of research from a variety of different performance contexts. Here we discuss how task constraints of different performance contexts (sport, industry, military, music) provide different specific information sources that individuals use to couple their actions when performing and acquiring skills. This relationship between performance task constraints and learning processes might help explain the traditional emphasis on performance curves and performance outcomes to infer motor learning [2]. The 
theory of ecological dynamics suggests that faithfully simulating in practice the specific goals, information and actions required in a performance environment can enhance motor learning functions in specific contexts. The representative simulation of intentions, information and action can help learners form specific information-movement couplings which is the basis of skilled behaviour in sport.

\section{ECOLOGICAL DYNAMICS AND GENERAL PRIN- CIPLES OF MOTOR LEARNING}

The theoretical rationale of ecological dynamics provides the foundation for our argument on the specificity of practice and principles of skill acquisition in particular contexts, such as sport, industry, art or military conflicts [3,4]. Traditional theories of motor skill acquisition have tended to emphasise the establishment and subsequent enrichment of internal representations that bring about relatively permanent changes in a learner's movement capabilities [2]. In accordance with this theoretical interpretation, the aim of practice is to increase the 'strength' of internal states (memorial representations of movements and perceptions), with researchers interested in understanding 'what' has been acquired to change the nature of the internal state [2]. In traditional theorising, the context of motor learning provides a platform for learners to gain performance-related feedback only to strengthen the specific knowledge content codified in an internal representation controlling behaviour. Traditional motor learning theories typically construe information as the correspondence (i.e. the codification) between objective facts in the world and subjective mental constructs.

In contrast, ecological dynamics emphasises that the most relevant scale of analysis for understanding human behaviours is the performer-environment relationship. Information sources from a particular performance context specify the actions that performers need to make, by affording opportunities to act [5]. The individuals' ability to identify such specifying variables and actualize affordances for action sustains successful performance in particular contexts. This process is founded on the establishment and subsequent refinement of information-movement couplings in achieving skilled adaptive behaviours. Elsewhere we have outlined the three key tenets that ecological dynamics provides as universal principles of motor learning, regardless of performance context [4]. These principles suggest that motor learning on different timescales occurs through the: (i) education of intention (which of a number of possible perceptions and actions performers intend to actualize); (ii) education of attention (attunement to the specifying variables); and (iii), calibration (adjustment of information to one's action capabilities) [6].

These principles underpin the process of adaptation to a specific performance environment, providing a platform for individuals to establish functional information-movement couplings, which form the basis of expertise in sport [1]. Learning design in sport can be enhanced by faithfully representing the ecological constraints which are assumed to underpin intentionality in performance and defining specifying and non-specifying variables [6]. The education of intention is, therefore, an important principle that guides each learner towards particular informational variables that need to be detected to support actions. During motor learning, the intentions of an individual need to correspond to a task goal, and each learner is challenged to coordinate the abundant perceptual and motor system degrees of freedom in achieving a specific task goal, whether playing an instrument, rolling a cigar or intercepting a pass in team sports. Due to the dynamic nature of many tasks, during learning, the same intention can result in the detection of many different informational variables. The process of attending to a more functional variable or combination of variables (specifying variables) occurs by educating the learner's attention or perceptual attunement $[7,8]$. With task experience, performers learn to attend to more functional information variables for achieving a specific performance goal (e.g., the sound of a machine being operated, the feel of a keyboard or the time needed to close the gap between a team mate and a defender in team sports). Through perceptual attunement each learner individually selects which sources of information to attend to in which performance situations and when to attend to these variables. With practice, performers converge from sources of information that may be only partly useful in one particular situation (non-specifying perceptual variables) to specifying information sources which support behaviours in different performance contexts. Calibration, or the scaling of the perceptual-motor system to information, is important, because the perceived arrays of energy surrounding each individual do not inform him/her about his/her ability to act on that specific information. Learning to calibrate information to one's action capabilities during practice is an important task for learners to help them perceive the environment in intrinsic movement system units, that is, in functional terms that allow them to discriminate what they can and cannot do during performance. This is of special importance since body dimensions and action capabilities are not fixed, but often change across both short and long time scales [9]. Calibration during practice is necessary for performers to perceive the environment in intrinsic movement system units even after changes in body dimensions and action capabilities. Successful calibration results in actions that are appropriately scaled to a property to be perceived, independent of which informational variables are used to support perception and action. Research in sport performance contexts has demonstrated that individuals vary in the visual strategies used to undertake specific performance tasks [10], or in the information sources they use to satisfy different intentional constraints [11]. In addition to perceiving information with reference to their own action capabilities, performers are also able to perceive information scaled to the action capabilities of significant others (e.g., teammates or opponents in sport), which in turn may constrain or inform their own actions [12].

\section{MOTOR LEARNING IN SPORT: SPECIFIC INSTAN- TIATIONS OF THE TENETS OF ECOLOGICAL DY- NAMICS}

In different performance contexts such as military, industrial, artistic or sport environments, the key tenets of motor learning outlined here provide a relevant foundation for learning design. These general principles become instantiated during practice in specific performance environments for individuals, and, as noted, all three tenets ascribe a powerful role to functional sources of information for action and 
perception to regulate performance. For example, in sport, the learner needs to understand which actions to perform when (e.g. in ice climbing when and how to use a pick to stabilise an existing position or to explore new ice surfaces, [13]; or in volleyball when to dig, set or spike a ball). Particular intentions are predicated on information from the performance environment to which learners become attuned with experience. When learners become more experienced in attuning to functional informational variables they move from those sources which do not specify actions (e.g., the flight of a cricket ball bowled at $140 \mathrm{kph}$ by a fast bowler) to sources of information that are more functional (i.e. the runup and delivery actions of that fast bowler prior to release) [14]. In fast ball sports, the process of attunement to earlier informational variables from the kinematic motions of an opponent are more functional because it allows a performer more time to act under increasing spatial-temporal constraints.

Information from actions shapes this process of information-movement coupling, even in learners who cannot yet successfully perform an action [15]. For example, in ball games, implements such as racquets or bats alter a performer's effective body dimensions in the short term (through an increased reach distance). Action capabilities change across longer time scales as a result of development, ageing and training. When body dimensions and action capabilities change, for example through development or ageing, actions that were once possible may become less possible or vice-versa [9]. In the learning process, calibration and recalibration are necessary to maintain functionality of perception. These processes can establish and update the mapping between the sub-systems in which the relevant properties of the environment are perceived (e.g., visual or proprioceptive), and the sub-systems with which an action is achieved (reaching and grasping or locomotion).

To summarise, the entangled, complex relationship between the processes of intentionality, perception and action forms the basis of motor learning, providing the principles and practice to guide learning design in specific performance contexts. This cyclical and interacting relationship between intentionality, perception and action can shape emergent behaviours during motor learning in sport. The specific instantiation of the general motor principles in different performance contexts like sport is relevant because one's intentions, actions and perceptions adhere to the extraordinary boundary constraints of performance [1].

\section{PRACTICAL IMPLICATIONS OF TENETS OF ECO- LOGICAL DYNAMICS FOR LEARNING DESIGN IN SPORT}

The key tenets of educating intentionality of learners, while they also become attuned to functional informational variables to regulate and calibrate their actions, have some significant practical implications for learning design in sport. First, sport scientists need to be aware of a potentially negative reductionist effect of theories of motor learning predicated predominantly on time spent in practice $[16,17]$. Practice volume is central to many prevalent perspectives on expertise acquisition, such as the 10,000 hour rule [18], the power-law of practice [19], and deliberate practice [17].
These traditional theories tend to solely focus on effects on learning of time spent practising (e.g., sheer quantity). From a practical perspective, these frameworks have rather overemphasised the value of repetitive practice trials, or volume of practice, to the exclusion of representative learning design and a focus on quality (fidelity) of practice [1]. To exemplify, in many ball sports, ball projection machines are used to increase the number of repetitive practice trials that a learner can undertake, without increasing the risk of injury to a team mate or coach in delivering a ball. However, our research has suggested that, in their current mode of use, prolonged exposure to projection machine practice tasks may encourage athletes to adopt a passive characteristic in practice by waiting for a ball to be projected, and fixating on the machine's projection mouth, rather than searching for specifying information sources [10,14]. More problematically, it is possible that learners become attuned to information sources (e.g., trajectories of ball flight) which are not as functional during competitive performance, leading to a predictive rather than prospective control strategy emerging when seeking to intercept a ball [14].

Recent work has shown that using projection machines in junior cricket batting led learners to re-organise their actions in their attempts to satisfy the new spatial-temporal task constraints of practice. Other studies have shown that use of projection machines in sports like tennis and cricket can create significant differences in timing and control of performers' actions compared to when facing a 'live' opponent [14, 20]. Developing junior cricket batters initiated key movements significantly later when playing against a projection machine set to the same speed $\left(\approx 28 \mathrm{~m} \cdot \mathrm{s}^{-1}\right)$ and with similar ball trajectory characteristics as a ball delivered by a 'live' performer. These delays in movement initiation resulted in significant adaptations in movement organisation and reduction in quality of bat-ball contact during interception [14]. These results exemplify how different sources of perceptual information present different action possibilities or affordances for performers to calibrate specific actions in sport and for this reason care should be taken in designing practice simulations $[21,22]$. Our investigations of the use of ball projection machines in learning has demonstrated that, even between two tasks which were, until recently, considered to be similar, functional differences exist between the movement patterns of learners. Batting against a ball projection machine is not the same task as batting against an individual bowling a ball, because the two distinct task constraints shape intentions, actions and perceptions in different ways. The way that practice aids, such as projection machines, change the ecological constraints of practice is a quintessential example of inferring information of learning processes from reductionist or non-representative tasks. Representative learning design emphasises the importance of designing practice simulations which maintain information sources and relevant actions in the learning environment so that functionality is enhanced [14]. Motor learning in sport needs representative design to be acknowledged as the generalization of task constraints in practice simulations to the constraints encountered in specific sport performance environments, such as team games, aquatic sports or outdoor activities [5, 23]. The principles guiding the generalisation of practice simulations to performance environments is predicated on 
the complex intertwined relations between intentions, actions and perception. An important aspect of learning design for performance in a specific context is the replication of the psychological conditions that can shape the behaviours of learners. For example, in sport, it is important for learners to experience how constraints of the competitive performance environment might shape their intentions, actions and perceptions. These intertwined regulatory features of behaviour in sport can alter as a result of factors such as performance anxiety, goal orientations and confidence [24]. Thus it may be considered that small-sided and conditioned games might be more functional than practice drills in the adaptive learning process that characterises sports [1].

In designing practice tasks that faithfully simulate performance environments an important challenge is to capture how intentions of learners shape perception and emergent movement patterns. For example, in the team game of association football, a basic movement pattern involves passing the ball to a teammate or shooting at goal. Static practice drills for acquiring skill in passing or shooting are reductionist and involve simple movement pattern repetitions in which the frequency of actions or volume of practice is emphasised [for a critique see 22]. But in such sport performance environments learners need to consider spatio-temporal sources of information when continuously adapting such motor movement patterns to performance task constraints. For example, it has been demonstrated that, in competitive team sports environments like futsal (a type of 5-aside indoor association football), the time for a defender to arrive at an interception point at the same time as the ball is an important constraint on the passing behaviours of attacking players. [25] Other work has shown that, in order for an attacker to shoot successfully at goal, he/she should promote a misalignment in a defender's position in between him/herself and the goal [26]. In 1vs1 subphases of association football and rugby union, successful dribbling behaviours are also highly constrained by the interpersonal distance and relative velocity of an attacker and a marking defender $[27,28]$. These studies have shown how the interpersonal coordination tendencies between competing performers shape the way that perception and action are coupled in completing a task. From the ecological dynamics perspective, the performance environment is perceived as opportunities to act (i.e., affordances), capturing the fit between performer constraints and the properties of the environment [29]. The continuous performer-environment interactions emphasise adaptive movement variability in performing basic motor skills. In team sports, inter-personal coordination is grounded on the players' ability to identify and calibrate specifying information for the action capabilities of teammates and opponents. The movement patterns assembled by a learner to achieve a specific task goal need to be geared to specific interpersonal coordination tendencies that emerge with specific opponents [30]. It is, therefore, imperative that learners in performance contexts like sport are exposed to critical sources of information which they can sample in practice conditions which have been designed to faithfully simulate performance contexts. In this respect, skill acquisition is likely to be enhanced not by repetitive practice drills for passing and shooting but by learning experiences in small-sided games against different opponents, with distinct action capabilities [1].
To conclude, in this commentary we have argued that ecological dynamics provides three key tenets which could form the basis of general principles of motor learning across a variety of different performance contexts. In different environments, like sport, these general principles need to be specifically instantiated in the ecological task constraints of performance. Competitive sport performance contexts are typically dynamic, requiring the representative design of learning tasks which contain information sources that have been faithfully simulated from specific performance environments. Learners need to learn to regulate their behaviours by becoming attuned to key information sources which act as affordances for actions. For this reason practice tasks in sport need to avoid reductionism, emphasise dynamic search activities of learners and faithfully maintain the complex intertwined relationship between intentions, actions and perceptions, in a managed way.

\section{CONFLICT OF INTEREST}

The authors confirm that this article content has no conflicts of interest.

\section{ACKNOWLEDGEMENTS}

None Declared.

\section{REFERENCES}

[1] Davids K, AraújoD, Hristovski R, Passos P, Chow JY. Ecological dynamics and motor learning design in sport. In: Williams AM, Hodges N, Eds. Skill Acquisition in Sport: Research, Theory \& Practice, $2^{\text {nd }}$ ed, London: Routledge, in press.

[2] Schmidt R, Lee T. Motor control and learning: a behavioral emphasis. $5^{\text {th }}$ ed. Illinois: Human Kinetics 2011.

[3] Dicks M, Davids K, Araújo D. Ecological psychology and task representativeness: implications for the design of perceptual-motor training programmes in sport. In: Hong Y, Bartlett R, Eds. Routledge handbook of biomechanics and human movement science. London: Routledge 2008; pp. 129-39.

[4] Araújo A, Davids K. What exactly is acquired during skill acquisition? J Conscious Stud 2011; 18(3): 7-23.

[5] Araújo D, Davids K, Hristovski R. The ecological dynamics of decision making in sport. Psychol Sport Exerc 2006; 7: 653-76.

[6] Jacobs D, Michaels C. Direct learning. Ecol Psychol 2007; 19: 32149.

[7] Gibson JJ. The ecological approach to visual perception. Boston, MA: Houghton Mifflin 1979.

[8] Gibson JJ. The senses considered as perceptual systems. Boston: Houghton Mifflin 1966.

[9] Fajen B, Riley M, Turvey M. Information, affordances and the control of action in sport. Int J Sport Psychol 2008; 40(1): 79-107.

[10] Croft JL, Button C, Dicks M. Visual strategies of sub-elite cricket batsmen in response to different ball velocities. Hum Mov Sci 2010; 29: 751-63.

[11] Dicks M, Button C, Davids K. Examination of gaze behaviors under in situ and video simulation task constraints reveals differences in information pickup for perception and action. Atten Percept Psychophys 2010; 72: 706-20.

[12] Stoffregen T, Gorday K, Sheng Y, Flynn S. Perceiving affordances for another person's actions. J Exp Psychol Hum Percept Perform 1999; 25: 120-36.

[13] Seifert L, Wattebled L, L'Hermette M, Hérault R. Inter-limb coordination variability in ice climbers of different skill level. Educ Phys Train Sport 2011; 1: 63-8.

[14] Pinder R, Davids K, Renshaw I, Araújo D. Manipulating informational constraints shapes movement re-organization in interceptive actions. Atten Percept Psychophys 2011; 73: 1242-54.

[15] Cañal-Bruland R, van der Kamp J. Action goals influence actionspecific perception. Psychol Bull Rev 2009; 16: 1100-5. 
[16] Davids K, Glazier P, Araújo D, Bartlett R. Movement systems as dynamical systems, the functional role of variability and its implications for sports medicine. Sports Med 2003; 33: 245-60.

[17] Ericsson KA, Krampe RT, Tesch-Römer C. The role of deliberate practice in the acquisition of expert performance. Psychol Rev 1993; 100: 363-406.

[18] Chase WG, Simon HA.Perception in chess. Cogn Psychol 1973; 4: 55-81.

[19] Newell A, Rosenbloom PS. Mechanisms of skill acquisition and the law of practice. In: Anderson JR, Ed. Cognitive skills and their acquisition. Hillsdale, NJ: Erlbaum 1981; pp. 1-55.

[20] Shim J, Carlton LG, Chow JW, Chae WK. The use of anticipatory visual cues by highly skilled tennis players. J Mot Behav 2005; 37: 164-75.

[21] Hristovski R, Davids K, Araújo D, et al. Constraints-induced emergence of functional novelty in complex neurobiological systems: a basis for creativity in sport. Nonlinear Dynamics Psychol Life Sci 2011; 15(2): 175-206.

[22] Vilar L, Araújo D, Davids K, Renshaw I. The need for 'representative task design' in evaluating efficacy of skills tests in sport: A comment on Russell, Benton and Kingsley. J Sports Sci 2010 [In Press].

[23] Davids K. The constraints-based approach to motor learning: Implications for a nonlinear pedagogy in sport and physical education. In: Renshaw I, Davids K, Savelsbergh GJP, Eds. Motor learning in practice: A constraints-led approach. Routledge: New York 2010; pp. 3-16.

[24] Davids K, Araújo D, Button C, et al. Degenerate brains, indeterminate behavior and representative tasks: implications for experimental design in sport psychology research. In: Tenenbaum G, Eklund RC, Eds. Handbook of sport psychology. $3^{\text {rd }}$ ed, Hoboken (New Jersey): John Wiley \& Sons, Inc. 2007; pp. 224-44.

[25] Travassos B, Araújo D, Davids K, Vilar L, Esteves P, Correia V. Informational constraints shape emergent functional behaviors during performance of interceptive actions in team sports. Psychol Sport Exerc 2012; 13: 216-23.

[26] Vilar L, Araújo D, Davids K, Travassos B. Constraints on competitive performance of attacker-defender dyads in team sports. J Sports Sci 2012; 30(5) : 459-69.

[27] Duarte R, Araújo D, Gazimba V, et al. The ecological dynamics of 1v1 sub-phases in Association Football. Open Sport Sci J 2010; 3: 16-8.

[28] Passos P, Araujo D, Davids K, et al. Interpersonal pattern dynamics and adaptive behavior in multiagent neurobiological systems: conceptual model and data. J Mot Behav 2009 ; 41(5): 445-59.

[29] Turvey MT. Action and perception at the level of synergies. Hum Mov Sci 2007; 26: 657-97.

[30] Vilar L, Araujo D, Davids K, et al. The role of ecological dynamics in analysing performance in team sports. Sports Med 2012; 41 (1): $1-10$

(C) Davids et al.; Licensee Bentham Open.

This is an open access article licensed under the terms of the Creative Commons Attribution Non-Commercial License (http://creativecommons.org/licenses/ by-nc/3.0/) which permits unrestricted, non-commercial use, distribution and reproduction in any medium, provided the work is properly cited. 